\title{
LA HEGEMONÍA DE LA TEMÁTICA SOBRE LA FORMA EN EL ESTUDIO DEL ENSAYO HISPANOAMERICANO
}

\author{
EUgENIA Houvenaghel \\ Fondo de Investigaciones Científicas, Flandes (Univ. De Gante) \\ Universidad Católica de Nimega
}

\section{INTRODUCCIÓN}

Parece comúnmente admitido que la atención suscitada por el ensayo hispanoamericano, según observa Mejía Sánchez (1971: 5-13), ha derivado, mucho más, del interés por los aspectos ideológicos desarrollados en los mismos que por la forma dada a estos contenidos. Stabb, por ejemplo, en su libro In quest of identity (1967), estudia la evolución del ensayo hispanoamericano, desde 1890 a 1960, bajo la perspectiva de la historia de las ideas más que bajo el punto de vista de los aspectos literarios; efectivamente, en la introducción de esta obra, ya se recoge una de las principales ideas que han guiado la inmensa mayoría de los estudios sobre el ensayo en aquel continente: "Though I am concerned with the essay as a vehicle of expression, the focus of this study lies more in the area of ideas -of intellectual history set against the backdrop of the total culture- than it does in the area of literature per se» (1967: 11).

Basta con echar un rápido vistazo a los estudios críticos sobre el conjunto de la ensayística hispanoamericana, para comprobar cómo, en su mayoría, éstos han sido llevados a cabo por investigadores interesados, fundamentalmente, en la filosofía y en la historia del pensamiento: El pensamiento hispanoamericano de José Gaos (1944), A Century of LatinAmerican Thought de Crawford (1944), Dos etapas del Pensamiento en Hispanoamérica de Zea (1970).

Aunque, evidentemente, existen obras de carácter general sobre la historia del género ensayístico en Hispanoamérica -recordemos Del ensayo americano de Medardo Vitier (1945), el Índice crítico de la literatura hispanoamericana de Zum Felde (1954) o la Breve historia del ensayo hispa-

Rlit, LXIV, 128 (2002), 525-537 
noamericano de Mead (1956) - en las que es posible hallar breves referencias a los aspectos estilísticos del género, todavía está lejana la consideración y valoración del ensayo hispanoamericano desde el punto de vista literario. Asimismo, cuando dirigimos nuestra atención a las monografías centradas en la obra de cada uno de los ensayistas hispanoamericanos, comprobamos que son muy pocos los que cuentan con un estudio estilístico acorde con sus méritos ${ }^{1}$.

Llegamos, así, a la confirmación de que existe una tendencia general en los estudios sobre el ensayo americano que consiste en privilegiar el pensamiento sobre la forma: en efecto, la crítica tiende, claramente, a inclinarse en favor de los contenidos ideológicos del ensayo, en detrimento de los valores expresivos del mismo y, por lo general, rehúsan, además, vincular los aspectos formales del texto ensayístico con su mensaje ideológico.

Intentando ofrecer, en este breve estudio, una respuesta convincente al porqué de tal situación, argüiremos, como hipótesis, que el particular lugar que la temática ha venido ocupando en el ensayo americano constituye una de las causas de aquella negligencia respecto de la forma. Para ello, profundizaremos en el lugar que, tradicionalmente, la temática ha ocupado en el género ensayístico, antes de resaltar las peculiaridades de ésta en el ensayo de aquellas tierras. A lo largo de nuestro trabajo, recurriremos, ocasionalmente, a la comparación con los ensayos francés, inglés y español, sin otra pretensión que la de resaltar, mediante el contraste, las características distintivas del género ensayístico en Hispanoamérica.

En este capítulo, consideraremos, únicamente, la influencia que el desarrollo de la temática ha ejercido sobre el estudio de este género en Hispanoamérica, dado que se trata de un factor exclusivo del ensayo en aquellos países. Obviamente, existen otros muchos aspectos que, desde el punto de vista del ensayo, en general, favorecen la desatención hacia los análisis estilísticos y que convendría tener muy en cuenta. En efecto, tradicionalmente, se ha considerado el ensayo como un tipo de texto ancilar respecto a la literatura, esto es, como un vehículo de expresión mucho más cercano a la filosofía o la ciencia que a la literatura. Bajo esta perspectiva, la idea de un estilo «discursivo» parece reducir, considerablemente, las posibilidades artísticas del género $\mathrm{y}$, sin embargo, la discursividad no se opone, necesariamente, a la riqueza artística, como bien explicó Anderson Imbert

\footnotetext{
${ }^{\prime}$ Existen, evidentemente, notables excepciones: pensemos, por ejemplo, en el espléndido ensayo de Unamuno sobre el estilo de José Martí o el valioso trabajo de Anderson Imbert (1948), titulado El arte de la prosa en Juan Montalvo. Con todo, estos casos aislados no actúan, en modo alguno, como contrapeso frente a la mayoría de los estudios sobre el ensayo hispanoamericano. Consúltese la bibliografía sobre el estudio del ensayo latinoamericano de Gómez Martínez 1976; Horl 1980; Rey de Guido 1985; Sanjuan 1954.
} 
(1946: 123-4) en aquella definición del ensayo en la que, de manera explícita, alude a la forma artística del género, diciendo que «el ensayo es una estructura lógica, pero donde la lógica se pone a cantar».

\section{TEMÁtICA DEL ENSAYO}

Pese a todas las consideraciones anteriores, conviene destacar que la temática no constituye un elemento decisivo a la hora de definir el género ensayístico: en efecto, el tema no determina si un texto pertenece o no a este género. Más aún, nuestro género se caracteriza, justamente, por su falta de restricciones temáticas; tanto es así, que un ensayo puede tratar, literalmente, cada asunto (Hamilton 1972: 10; Earle y Mead 1973: 9; Rey de Guido 1985: 9; Oviedo 1990: 11). Basta hojear cualquier antología de ensayos para comprobar la variedad de asuntos tratados en los mismos. Al margen de ello, el ensayista es libre para combinar, dentro del propio ensayo, dos o más temas, así como para estudiar cierto fenómeno a la luz de otra disciplina (Oviedo 1990: 12 y Berger 1964: 82-83). Montaigne expresa la total libertad que goza el ensayista a la hora de decidir sobre la temática, señalando: «no estoy obligado a ser perfecto ni a concentrarme en una sola materia; varío cuando bien me place» (Aullón de Haro 1992a: 9). Así, pues, enfocando el ensayo a la luz de sus aspectos temáticos, parece imposible aproximarse a la esencia del género ${ }^{2}$; para hallar un rasgo definitorio y específico del género es preciso desplazar el foco desde el tema hacia el autor.

Berger (1964: 63-64) y Aullón de Haro (1987a: 105) subrayan, en este sentido, que el carácter ensayístico de un texto no depende de la materia tratada sino de la perspectiva que el autor adopta, esto es, del «sello personal» (Rey de Guido 1985: 63). Oviedo (1990: 12), por su parte, insiste en la supremacía del autor sobre el tema: el ensayista está, continuamente, sobrepasando los límites del tema merced a la elaboración individual y subjetiva del mismo. A menudo, se tiende a oponer el valor objetivo del artículo científico al carácter subjetivo propio del ensayo, al destacar, por ejemplo, que un gran invento científico podría estar al alcance de cualquier sabio mientras que dos ensayistas no podrán, nunca, redactar dos grandes ensayos completamente idénticos (Berger 1964: 20). En efecto, el desafío del género ensayístico consiste, justamente, en extraer algo nuevo

\footnotetext{
${ }^{2}$ Por eso Berger sostiene que el tema no puede servir de criterio para una clasificación válida de ensayos y ataca, así, la clasificación temática de Just, que constituye una ordenación del ensayo en grupos (cultura, biografía, literatura y vida concreta). Berger (1964: 95 y ss.) explica que los intentos por clasificar los ensayos de modo temático no han conducido a resultados satisfactorios, porque lo que cuenta en la constitución del ensayo no es el tema, sino la perspectiva del autor.
} 
o sorprendente de un tema trillado y banal, en examinar las cosas, como dice Montaigne, por el lado más inusitado (Aullón de Haro 1992a: 9). La aproximación original, explica Wilperts, hace que siempre merezca la pena leer un ensayo, incluso si la opinión defendida ya ha sido superada desde el punto de vista científico (Berger 1964: 7).

Si dirigimos nuestra atención hacia el ensayo tradicional europeo, comprobamos, efectivamente, cómo la temática abordada en los ensayos nos sorprende por su notable heterogeneidad, hasta el punto de poder afirmar que no existe una preocupación temática central propia del género ensayístico. Ahora bien, pese al lugar secundario que la temática ocupa en el ensayo tradicional de Francia o Inglaterra, sí es posible reconocer un asunto recurrente en el ensayo hispanoamericano, circunstancia que, por tanto, lo aleja de las características del género en la Vieja Europa. En efecto, esta unidad temática se constituye sobre la base de una reflexión constante y reiterada acerca de «lo propio» (Rey de Guido 1985: 118), «la realidad y problemática nacional», esto es, en torno a «la formación del país» (Gómez Martínez 1958: 17). Tanto es así, que este género ha contribuido, desde su nacimiento en Hispanoamérica, a un mejor conocimiento de la identidad americana, así como a la definición de la diferencia americana frente a Europa y los EE.UU ${ }^{3}$ (Oviedo 1990: 23). Esta preocupación central que constituye la base de todo americanismo podría ponerse en relación con la conciencia crítica acerca del propio país, pensamiento que domina la ensayística española, de manera que el «problema de América» encontraría su eco en el «problema de España». Los problemas de identidad que se planteaban a España al fin del siglo XIX se asemejan a los de la América conquistada y colonizada por ella, si bien, en este último caso, estaban implicados, también, los problemas respecto al mestizaje de etnias y culturas ${ }^{4}$.

Pensemos, por lo que se refiere a España, en las meditaciones de la generación del 98 en torno a este país, destacando, a modo de ejemplo, las reflexiones de Miguel de Unamuno (1970) sobre la crisis que atraviesa

\footnotetext{
${ }^{3}$ Hamilton (1972: 10) rechaza la unitematicidad del ensayo americano y parece considerar como ofensiva la insistencia de la crítica en la identidad americana como tema dominante del ensayo. "Y cuando todavía esa selección [la selección de ensayos que constituye esta antología] añade otra característica, cual es la de elegir trozos que giran en torno del mismo tema de América, presenta una imagen trunca del pensamiento nuestro, ¡como si los ensayistas fueran sólo periodistas empecinados en machacar sobre un solo tema para desfogar un resentimiento de mestizos! [...] Quiero, además, dar ejemplos de diversos tipos de ensayo cultivado en las repúblicas hispanoamericanas; porque para ser escritores americanos no necesitan escribir sobre temas americanistas. Hay buenos especialistas en filosofía o crítica literaria, historia o sociología, arte o política».

${ }^{4}$ Zea elabora la comparación entre los problemas de identidad de la península ibérica e Hispanoamérica con más detalle en «La identidad en el pensamiento iberoamericano» (1990: 57-68).
} 
la sociedad española y sobre la renovación de la que tanto precisa el país y valgan, por su ilustrativo carácter, títulos como «La crisis del patriotismo», «Sobre la europeización», «La juventud intelectual española», «Sobre el marasmo actual de España», y «El individualismo español». También Ortega y Gasset (1966) se ocupó de describir la dramática situación a la que se enfrentaba España, constatación que dio lugar a una enriquecedora y valiosa redefinicón de «lo español». Ensayos como «España y Europa», «La España oficial y la España vital», «La organización nacional», «Nuestra actuación política», «España, problema político», «Los dos patriotismos» nos ponen sobre la pista del tema que centra la atención de los pensadores hispanos, a saber, España y la identidad española, o, lo que es lo mismo, la esencia del país y de sus ciudadanos.

Otro tanto ocurre en el ámbito del ensayo hispanoamericano donde, para ilustrar la recurrencia temática propia 'del género en aquellas tierras, examinaremos una antología del ensayo americano que lleva por título El ensayo en Hispanoamérica (Vázquez 1946). Esta obra ofrece una visión panorámica - $\mathrm{y}$ cronológicamente ordenada - de la evolución del género, en la que se incluyen ensayistas tan sobresalientes como Andrés Bello o Alfonso Reyes. Pues bien, sobre 19 autores hispanoamericanos y 38 ensayos seleccionados, sólo tres de ellos no abordan ningún aspecto relacionado con la problemática nacional o americana ${ }^{5}$. Así las cosas, títulos del tipo «Las Repúblicas Hispano-Americanas» de Bello; «Ventura de América» de Lastarria; «La República en América» de Montalvo; «Nuestros indios» de González Prada; «El criollismo» de Blanco Fombona; «El mestizaje» de Vasconcelos o «Posición de América» de Reyes dominan la totalidad de la obra en cuestión.

Hemos visto, pues, cómo, en el ensayo tradicional europeo, la temática ocupa, precisamente, el lugar secundario que le hemos atribuido en la parte introductoria de este trabajo, y cómo esta circunstancia se torna en el elemento definitorio del género en el ámbito europeo. En el ensayo hispánico, en cambio, la temática ocupa un lugar de privilegio. Si tenemos en cuenta la presencia recurrente de determinados puntos, la temática acabará, incluso, por convertirse en el rasgo genérico más destacado en el ensayo hispanoamericano y español.

\section{MOMENTO DE APARICIÓN DEL ENSAYO}

Al margen de esta especial importancia concedida a la temática, también la tardía aparición del ensayo en España lo aproxima más al ensayo

${ }^{5}$ Estos tres casos excepcionales son puramente literarios y comentan, respectivamente, Hamlet, la obra de Ercilla y Zúñiga y la de Gutiérrez Nájera. 
hispanoamericano que al ensayo clásico europeo. Efectivamente, ya en los siglos XVII y XVIII, Europa conoce, con la excepción de España - donde el género florece, por primera vez, con la generación del 98-, una rápida difusión del género (Marichal 1971: 12, 18-20; Oviedo 1990: 19; Rey de Guido: 81). Así pues, atendiendo a razones cronológicas, también cabe distinguir entre el ensayo español, por un lado, y el ensayo francés e inglés, por otro. En este mismo sentido, cabe indicar que el ensayo hispanoamericano también conoció su auge durante los siglos XIX y XX, si bien su nacimiento es anterior al del ensayo hispano, dado que se remonta a comienzos del siglo XIX, en el mismo momento en el que se inician las luchas independentistas ${ }^{6}$.

Este momento de aparición que, para España, hemos descrito como «tardío», podría calificarse, como explica Arciniegas (1993: 331), en el caso de Hispanoamérica, como «temprano» ${ }^{7}$. El ensayo hispanoamericano aparece, efectivamente, como primer género de la literatura propiamente americana: lo crean los mismos fundadores de la conciencia cultural y literaria de América. Por lo general, señala Oviedo (1990: 22), la ensayística apa-

${ }^{6}$ El nacimiento de la ensayística hispanoamericana puede situarse en tres diferentes momentos: 1) en la época colonial (Arciniegas 1993), 2) en la época de las luchas por la independencia, al inicio del siglo XIX (Oviedo 1996, Zum Felde 1954), 3) en 1900 con Ariel (Loveluck 1976). Dos citas representativas de las posturas más extremas. Arciniegas escribe (1993: 331 y 410-411): «Ensayos se han escrito entre nosotros desde los primeros encuentros del blanco con el indio, en pleno siglo XVI, unos cuantos años antes de que naciera Montaigne. [...] En rigor, el ensayo sobre el Nuevo Mundo se escribe en la primera década del siglo XVI por los propios exploradores. [...] De todo lo que luego se ha dicho en los ensayos escritos durante el siglo XIX hay anticipos nada despreciables en aquellos textos primitivos preñados por el asombro de la revelación.» Loveluck, al contrario, opina (1976: 7): «Por un afán casi arqueológico casi todos los libros y estudios que tratan del ensayo hispanoamericano invierten páginas y capítulos en trazar la prehistoria de tan prestigiosa función literaria y perfilan sus orígenes o remotas manifestaciones en crónicas y textos de la Conquista, el Coloniaje o el periodo de las luchas de Independencia. Buena ilustración de lo que es gastar pólvora en gallinazos: porque si en Europa el ensayo se configura con rasgos maduros a finales del XVI, en Hispanoamérica, a pesar de anuncios y 'antecedentes' que no deseamos preterir, exhibe sus características definitivas en las cercanías del 900. [...] La fecha de Ariel -el simétrico 1900 - sería conveniente como espacio-límite en que el ensayo, tras esfuerzos cimeros como los de Sarmiento, González Prada y Montalvo, entre muchos, recibe una configuración definitiva en el ámbito nuestro [...]». La mayoría de los estudiosos del ensayo hispanoamericano, no se atreven a excluir de sus filas a figuras de la talla de Bello, Sarmiento, Montalvo y Hostos. Por nuestra parte, consideramos, con Oviedo y Zum Felde, que el ensayo hispanoamericano nace con las luchas por la independencia.

7 «Sorprende», dice Arciniegas (1993: 331), «a primera vista, esta anticipación, cuando hay otros generos literarios que sólo aparecen en América tardíamente (la novela, la biografía). La razón de esta singularidad es obvia. América surge en el mundo, con su geografía y sus hombres, como un problema. Es una novedad insospechada que rompe con las ideas tradicionales. América es ya, en sí, un problema, un ensayo de nuevo mundo, algo que tienta, provoca, desafía a la inteligencia». 
rece como último género literario, coincidiendo con el establecimiento y la consolidación de una civilización ya avanzada. Como consecuencia, y es el caso de Inglaterra o Francia, la imaginación de la poesía y de la narrativa influyen en la temática y constitución de la ensayística. En el caso hispanoamericano, en cambio, el ensayo ejerce gran influencia en la imaginación de poetas y narradores (Corvalán 1967: 63). Así las cosas, se puede concluir que el ensayo hispanoamericano, merced a su temprana aparición, ha desempeñado un papel excepcional y central en la evolución cultural y en el desarrollo de la civilización americana.

\section{FUNCIONALIDAD DEL ENSAYO}

Una vez apuntadas las diferencias cronológicas en lo que al auge del ensayo europeo e hispánico se refiere, volvamos sobre aquella diferenciación temática a la que aludíamos anteriormente. Esta debe entenderse bajo la perspectiva del grado de dependencia o independencia que presenta la temática del ensayo con respecto a la realidad socio-política. Los ensayos europeos, esto es, los correspondientes al ámbito franco-británico, pueden describirse como «reflexiones de carácter independiente» (Martínez 1958: 17), en tanto que la temática del ensayo americano aparece, por lo general, fuertemente ligada a la realidad inmediata (Zum Felde 1954: 18; Rey de Guido 1985: 118). En efecto, son pocos los ensayos americanos dedicados a la teoría o a la filosofía puras, de manera que cabría concluir que es el contexto específico (político, cultural, social y económico) el principal motor que guía el desarrollo del desarrollo del género ensayístico en América. Como dice Arciniegas (1993: 333): «El ensayo no es un divertimiento literario, sino una reflexión obligada a los problemas que cada época nos impone. Esos problemas nos desafían en términos más vivos que a ningún otro pueblo del mundo».

He aquí algunos ejemplos de ensayos pertenecientes al ámbito hispanoamericano y que ilustran a la perfección lo que acabamos de señalar. A través de su ensayo «Política agraria de la república», Mariátegui, sin ir más lejos, reclama la redistribución de la propiedad agraria en Perú (Brown y Jassey 1968: 63-68). «Biblioteca y escuela», de Gabriela Mistral, denuncia, por su parte, la ausencia de bibliotecas serias y extensas en América (Brown y Jassey 1968: 158-167). Justino Fernández, a su vez, describe, en «Significación de Orozco», la gran influencia que las pinturas murales del célebre artista mexicano ejercieron sobre los acontecicimientos políticos (Brown y Jassey 1968: 252-262) mientras que, en «La revolución mexicana», Zea critica la manera en que las películas hispanoamericanas de carácter histórico deforman la realidad de la revolución (Brown y Jassey 1968: 168-176). 
El análisis temático de una antología como Selected English essays (Peacock 1903), que reúne ensayos ingleses escritos por autores que van desde Francis Bacon hasta Robert Louis Stevenson, revela una notable preferencia por los asuntos de índole metafísica o moral («Of Truth», «Of Death», «Of Revenge», «Of Adversity», «Of Friendship») o bien por temas de tipo humorístico ( $«$ A Bachelor's complaint of the Behaviour of Married People», «On the Graces and Anxieties of Pig-driving», «On getting up on Cold Mornings»). Los temas predilectos del padre del ensayo francés, por su parte, comparten esta preferencia por los asuntos metafísicos o morales («Que philosopher c'est apprendre à mourir», «De la moderation», «De l'utile et de l'honneste», «Du repentir» et «De la vanité») y lo mismo puede decirse de ensayistas franceses posteriores como Méré, La Rochefoucauld, La Bruyère o el propio Pascal ${ }^{8}$.

Intentando hallar una respuesta al porqué de esta diferencia entre el ensayo europeo y el hispánico, proponemos, con Gómez Martínez (1958: 17), la idea que la temática franco-británica se revela independiente de las circunstancias históricas, porque los autores franceses e ingleses encuentran sus países lo suficientemente «hechos y cultivados». Muy distinto es el caso de los ensayistas del mundo hispano. América, en el momento del nacimiento del ensayo, apenas está tomando conciencia de sí misma, y el ensayo español florece, justamente, en una España marcada por el nefasto y desastroso año de 1898. Tanto América como España atraviesan, pues, épocas de crisis, de decadencia o de autocrítica, de modo que nos hallamos frente a naciones aún por hacerse y definirse.

Llegamos, así, a un factor crucial a la hora de explicar la distinta evolución temática de los ensayos europeo e hispánico: su funcionalidad ${ }^{9}$. En efecto, el ensayo americano muestra, por lo general, una clara intención política, como observan Brown y Jassey (1968), Hamilton (1972), Loveluck (1976), Rey de Guido (1985: 118), Vázquez (1972: 9) y Oviedo (1990: 21). El ensayo es utilizado en América como un arma en la campaña para alcanzar una América mejor. En este sentido, Earle y Mead insisten en que el ensayo no es un «simple pasatiempo» (1973: 23) y que, a menudo, los ensayistas «no distinguían mayormente la actividad política de la actividad literaria» (1970: 30). Los ensayistas americanos, según apunta Rey de Guido (1985: 28), se empeñan en fomentar los cambios ideológicos, y de comportamiento en el público y, mediante el lenguaje empleado en sus ensa-

\footnotetext{
${ }^{8}$ Para una visión de conjunto de los moralistas franceses, véase Bauër 1962.

${ }^{9}$ Cfr. Portuondo (1975: 5-23): «Hay una constante en el proceso cultural latinoamericano y es la determinada por el carácter predominante instrumental -Alfonso Reyes diría «ancilar»- de la literatura, puesta, la mayor parte de las veces, al servicio de la sociedad. [...] Desde sus inicios, el verso y la prosa surgidos en las tierras hispánicas del Nuevo Mundo revelan una actitud ante la circunstancia y se esfuerzan en influir sobre ella».
} 
yos, los intelectuales tratarán de persuadir a su auditorio para transmitirle ciertas ideas y, en suma, para «encender los ánimos».

Es preciso remontarse en el tiempo hasta las raíces del ensayo americano para ver cómo el auge inicial de este género tiene lugar en circunstancias muy peculiares. Rey de Guido (1985: 26) observa, en este sentido, que, en Hispanoamérica, nacen juntas la historia política - con sus luchas emancipadoras - y la historia literaria. De ahí que la literatura americana vea la luz en el seno de la propia evolución política, de manera que no puede hablarse de una literatura autónoma sino funcional. De esta manera, aparecen ligados los tres elementos hasta ahora señalados: el tema de América, la fuerte vinculación con la realidad histórica y la función política.

Examinemos, a continuación, algunos casos ilustrativos, en los que diversos ensayistas americanos, utilizando un lenguaje incitador, afirman y valorizan la identidad americana para alcanzar, así, el fin político de la independencia, de la libertad de pensamiento y del progreso. Sánchez Peláez ( «La gente y la mente» en Brown y Jassey 1968: 222), por ejemplo, intenta convencer a su público de la necesidad de aceptar las aportaciones de los extranjeros a la sociedad americana: «No debe nunca regateárseles [a los «buenos» extranjeros] el respeto a que se han hecho acreedores en una colectividad a la cual han dado mucho sin quitar absolutamente nada.» Picón Salas («Proceso del pensamiento venezolano» en Brown y Jassey 1968: 210), por su parte, procura encauzar la actitud del público frente a la tradición cultural: «Es ahora el instante de volver por esa tradición cultural que perdimos, pero que vivió con anhelo constructivo en algunos de los mejores y excepcionales hombres que ha dado el país. Contra el empirismo, la violencia, la eterna sorpresa y la aventura criolla podríamos invocar la inteligencia que planea.» Leopoldo Zea («La revolución mexicana» en Brown y Jassey 1968: 174) responsabiliza a los mexicanos al sentenciar que «nuestra revolución necesita la solución de los problemas que preocupan a esa Iberoamérica de la que formamos parte. Nuestros problemas son sus problemas: nuestra constitución histórica, cultural, política y social es la misma, de aquí que nuestra experiencia tenga para ella la importancia que tiene.» Y, por último, citemos el caso de Gutiérrez («La revolución contra el miedo» en Brown y Jassey 1968: 150), quien estimula al pueblo colombiano para superar el «gamonalismo» feudal, autoritario y provincial y llegar, por este camino, a una nueva política.

Dicho esto, ya es posible trazar la línea evolutiva de las distintas funciones que el género ensayístico ha cumplido desde sus orígenes europeos hasta su implantación en Hispanoamérica. En este sentido, Earle considera que el género del ensayo se «americanizó» y con ello no pretende sino indicar que el ensayo, que, en primer término, nació como una obra de arte, acabó por convertirse en un instrumento de acción (Rey de Guido 
1985: 37). Loveluck, por su parte, también describe la evolución desde el ensayo europeo, «contemplativo y sereno», hasta el ensayo hispanoamericano «con su voluntad programática, luchadora y eruptiva» (Rey de Guido 1985: 118).

¿Cuál era, pues, la función del ensayo europeo? En primer lugar, como explica Rhys (1959: 12), el ensayista procuraba deleitar al lector con «a pleasant peace of writing». Más adelante, como señala el propio Addison, uno de los maestros del género en Inglaterra, el ensayista busca instruir al público, vulgarizando la ciencia. Así, en su ensayo «Meditations in Westminster Abbey» (Peacock 1903: 123-126), por ejemplo, Addison recurre a una escena que al público le resulta sumamente familiar -el paseo entre las sepulturas - para presentar pensamientos acerca de la vida, la muerte y el más allá. En «The adventures of a shilling» (Peacock 1903: 118-122), por su parte, este mismo autor presenta algunos acontecimientos de la historia inglesa como si fueran vividos y contados por una moneda. Addison combina, así, el deleite estético y la instrucción. Dobrée concluye, acerca de la funcionalidad tradicional del ensayo, que este género surge, precisamente, en momentos en los que la ciencia corre el riesgo de terminar muy lejos del público, de manera que podría decirse que, en estas épocas de crisis, el ensayo viene a actuar como elemento de unión entre la ciencia y el público ${ }^{10}$.

\section{CONCLUSIONES}

Hemos visto, pues, cómo, en el ensayo americano, el tema llega a ocupar un lugar mucho más destacado que el que se le concedía el temprano género ensayístico europeo. Ello se hace más patente, si cabe, merced a la existencia de una precopuación temática central, ausente en el ensayo tradicional en Europa. Esta preocupación temática debe entenderse en relación con las circunstancias socio-politicas que rodearon el nacimiento de este género en tierras americanas: nos referimos al momento de toma de conciencia de aquellos países y a su posterior intento por definirse y consolidarse, allá por los inicios del siglo XIX. Como consecuencia de este parejo nacimiento de la autoconciencia y el género ensayístico, el ensayo es concebido, desde sus orígenes, como un medio idóneo a la hora de confirmar la propia identidad y como instrumento en la lucha por el reconocimiento. Así las cosas, el ensayo no se presenta como un género literario autónomo sino altamente funcional.

Simplificando, podemos distinguir, entonces, entre dos tipos de ensayís-

\footnotetext{
${ }^{10}$ Es oportuno recordar aquí la etiqueta de «pseudo-científico» que se adhiere al género ensayístico justamente a causa de esta función vulgarizadora.
} 
tica. Una tradicional, de temática variada, que cumple una función básicamente intelectual y que floreció en Europa durante los siglos XVI a XVIII y otro, americanizado, que se caracteriza por una unidad temática centrada en la propria identidad y por una activa función política, y que conoció su auge en los siglos XIX y XX. Este último tipo se presenta como un ensayo renovado, dominado y determinado, tanto respecto al tema como en cuanto a la función, por las circunstancias sociales, políticas e históricas del continente o de la nación. En otras palabras, América «admite» el género ensayístico tradicional que llega de la Vieja Europa pero lo modifica, y los ensayistas de la generación del 98 se inspirarán en esta interpretación modificada del género a la hora de expresar el llamado «problema de España». Juan Loveluck (1976: 9) resume, del siguiente modo, la evolución que acabamos de exponer:

En la traslación de las direcciones europeas del ensayo a Iberoamérica, muchos de sus rasgos esenciales sufren una metamorfosis, un amestizamiento y un acomodo a las necesidades y urgencias continentales: una problemática diversa gravita sobre la función y en larga medida trastorna los rasgos de origen, altera las líneas sabidas de su perfil. Sólo el que conoce las luchas y las angustias del mundo hispanoamericano, la necesidad de mantenerse alerta ante el expolio y la voluntad de «hacer la América» con las riquezas de nuestras naciones, puede comprender la torsión del ensayo desde su fórmula europea contemplativa y serena hasta su volunta programática, luchadora y eruptiva, inscrita en la mayoría de sus páginas.

Enlazando, pues, con nuestro punto de partida, podemos concluir que esta funcionalidad que el género adquiere en América se verá reflejada en torno a este nuevo tipo de ensayo, hasta el punto de que la crítica llegará a descuidar la esencia original del género - el sello personal del autor, la individualidad, la voluntad de estilo, la expresividad-, para centrarse en el nivel de los contenidos desarrollados, que corresponden, concretamente, a puntos de vista sobre la identidad de América.

\section{BIBLIOGRAFÍA}

MEJíA SÁNCHEZ, Ernesto. 1980. «Nota preliminar» en Reyes, Alfonso, O.C. t. XV: 7. STABB, Martín. 1967. In quest of identity. Chapel Hill: The University of North Carolina Press.

GaOS, José. 1944. El pensamiento hispanoamericano. México: El Colegio de México.

CRAWford, WILliam REX. 1961. A Century of Latin American Thought. Cambridge Massachusetts: Harvard University Press.

ZEA, Leopoldo. 1970. The Latin-American Mind. Norman: Oklahoma Press.

Vitier, MEdardo. 1945. Del ensayo americano. México: Fondo de Cultura Económica ZUM FELDE, Alberto. 1954. Índice crítico de la literatura hispanoamericano: los ensayistas. México: Guarania.

ANDERSON IMBERT, E. 1946. «Defensa del ensayo» en Ensayos. Argentina: Tucumán, 123-4. 
HAMILton, Carlos D. 1972. El ensayo hispanoamericano. Madrid: Ediciones Iberoamericanas.

EARLE, Peter y MEAD, Robert G. 1973. Historia del ensayo hispanoamericano. México: Andrea.

REY DE GUIDO, Carlos. 1985. Contribuciones al estudio del ensayo en Hispanoamérica. Caracas: Academia Nacional de la Historia.

OviEDo, José Miguel. 1990. Breve historia del ensayo hispanoamericano. Madrid: Alianza.

Berger, Bruno. 1964. Der Essay. Form und Geschichte. Bern: Francke Berlag.

AUllón DE HARO, Pedro. 1992. Teoría del ensayo: como categoría polémica y programática en el marco de un sistema global de géneros. Madrid: Verbum.

GÓMEZ MARTínEZ, José Luis (ed.). 1958. «Introducción» en El ensayo mexicano moderno. México: Fondo de Cultura Económica, 7-27.

VÁzQUEZ, Alberto. 1972. El ensayo en Hispanoamérica. New Orleans-México: El colibrí.

MARICHAL, Juan. 1971. La voluntad de Estilo: teoría e historia del ensayismo hispánico. Madrid: Revista de Occidente.

ARCiniegas, Germán. 1993. América ladina. México: Fondo de Cultura Económica.

CORVALÁN, Octavio. 1961. «El ensayo en América» en Modernismo y Vanguardia. New York: Las Américas.

BROWN, G. y JASSEY, W. 1968. Introducción al ensayo hispanoamericano. New York: Las Américas.

PEACOCK, William. 1903. Selected English Essays. London: Grant Richards.

LOVELUCK, Juan ${ }_{i}$. 1976. «El ensayo hispanoamericano y su naturaleza» en Los Ensayistas. I (1), 7-13.

BAUER, Gerard. 1962. «Préface» en Les moralistes français. Paris: Albin Michel, 9-36. 


\title{
RESUMEN
}

La hegemonía de la temática sobre la forma en el estudio del ensayo hispanoamericano, por Eugenia Houvenaghel.

Nuestro punto de partida es la comprobación de que la atención suscitada por el ensayo hispanoamericano, ha derivado, mucho más, del interés por los aspectos ideológicos desarrollados en los mismos que por la forma dada a estos contenidos. Intentando ofrecer una respuesta convincente al porqué de tal situación, argüimos, como hipótesis, que la particular unidad temática del ensayo americano - determinada por las circunstancias sociales, políticas e históricas del continente- constituye una de las causas de aquella negligencia respecto de la forma. Para reforzar nuestra argumentación, recurriremos a la comparación con los ensayos francés e inglés, que carecen de semejante unidad temática, por un lado, y con el ensayo español, que comparte las características temáticas del ensayo hispanoamericano, por otro.

Palabras clave: Ensayo, literatura hispanoamericana contemporánea.

\begin{abstract}
As a starting point, we observe that the critics of the Hispano-American essay have been far more interested by the ideologies exposed in the genre than by the stylistic form given to these contents. Trying to find a convincing explanation for this situation, we argue, as a hypothesis, that the particular thematic unity of the Hispano-American essay - determined by the social, political and historical situation of the continent- is an important cause of the negligence of stylistic aspects mentioned above. To reinforce our argumentation, we have recourse to the comparison with the French and English essay, which lack thematic unity, on the one hand, and with the Spanish essay, which shares the thematic characteristics of the Hispano-American essay, on the other hand.
\end{abstract}

Key words: Essai, Contemporary hispanoamerican literature. 